Article

\title{
Realizing a Democratic Community of Teachers: John Dewey and the Idea of a Science of Education
}

Jeff Frank

Education Department, St. Lawrence University, 23 Atwood Hall, Canton, NY 13617, USA; jfrank@stlawu.edu

Academic Editors: Paul Standish and SunInn Yun

Received: 20 September 2016; Accepted: 3 January 2017; Published: 5 January 2017

\begin{abstract}
In this paper, I make the case that John Dewey's philosophy of education aims to bring about a democratic community of teachers capable of creating a science of teaching. To make this case, I will do a three things. First, I will discuss Sources of a Science of Education and argue that this work is deeply connected to a work written at about the same time, Individualism Old and New. As I will show, the creation of a science of education is a complex endeavor that is premised on an ability to create a democratic community that reconstructs outmoded notions of individuality. Second, I will argue that the position put forward most directly in these later works is not a deviation from Dewey's overall educational philosophy by offering a reading Democracy and Education. I will argue that Dewey's thinking on a science of education is held nascent within Democracy and Education, especially in his discussion of individualism and democracy. Finally, I will assess whether and how current work in teacher education is consonant with Dewey's philosophical project, and draw out implications for philosophers of education.
\end{abstract}

Keywords: John Dewey; Democracy and Education; Sources of a Science of Education; teacher education; philosophy of education; teacher collaboration; educational policy; core practices

John Dewey's Sources of a Science of Education [1] has been receiving renewed attention from teacher educators in recent years [2]. In particular, teacher educators are interested in making the attempt to find "core practices" that form the basis of effective teaching and-once located-more effectively teach these practices to future teachers [3-5]. Though teacher educators have returned to Dewey in order to realize the promise of a science of education, philosophers of education have not yet engaged with what has become one of the most prominent discourses in teacher education or Dewey's work on creating a science of education. While philosophers of education are quick to note how Dewey stresses the uncertain nature of teaching [6-8], less attention is paid to Dewey's constructive project of creating a science of teaching. Intuitively—or maybe initially—something feels philosophically suspect about creating a science for something as complicated, context-based and personal as the work of teaching $[9,10]$. As such, it seems problematic to connect the work of Dewey with recent developments in teacher education aimed to do something like this [11]. In this paper, I hope to show that our intuitive-or initial-feeling may be off base. My goal is to demonstrate that Dewey-while recognizing the complexities and uncertainties of teaching-thought it was important to make the effort to create a science of education.

To make this case, I will do three things. First, I discuss Sources of a Science of Education and argue that this work is deeply connected to a work written at about the same time, Individualism Old and New [12]. As we will see, the creation of a science of education is a complex endeavor that is premised on an ability to create a democratic community that reconstructs outmoded notions of individuality. Second, I argue that the position put forward most directly in these later works is not a deviation from Dewey's overall educational philosophy by bringing our attention to core passages from Democracy and Education [13]. I will make the case that Dewey's thinking on a science of 
education is held nascent within Democracy and Education, especially in his discussion of individualism and democracy. Finally, I assess whether and how current work in teacher education is consonant with Dewey's philosophical project, and draw out implications for philosophers of education.

\section{Individualism and the Work of Teaching}

As Dan Lortie observed in his classic sociological study Schoolteacher [14], the work of teaching is generally marked by individualism. Teachers work in isolation from each other, and-in fact-seem to be rewarded for not collaborating [15]. Though strides have been made in the direction of teacher collaboration since Lortie wrote [16,17], it is hard to argue that Dewey's thinking in his 1929 Sources of a Science of Education does not remain relevant. Dewey worried that we focus on the exceptional individual teacher to the detriment of teaching. Instead of working to make teaching better-and so the lives of the largest possible number of students better-the objection is made that if we worked on teaching (in general), we would lose, or level down, what is unique and special about those individual teachers who touch the lives of the students who experience the exceptional teacher's presence. However, Dewey notes:

what is overlooked by the objector is that the successes of such individuals tend to be born and to die with them: beneficial consequences extend to those pupils who have personal contact with such gifted teachers. No one can measure that waste and loss that have come from the fact that the contributions of such men and women in the past have been thus confined, and the only way by which we can prevent such waste in the future is by methods which enable us to make an analysis of what the gifted teacher does intuitively, so that something accruing from his work can be communicated to others. Even in the things conventionally recognized as sciences, the insights of unusual person remain important and there is no leveling down to a uniform procedure. But the existence of science gives common efficacy to the experiences of the genius; it makes it possible for the results of special power to become part of the working equipment of other inquirers, instead of perishing as they arose [1] (pp. 4-5).

This is a long quote, but it-in many ways-gets to the heart of Dewey's argument. Dewey is concerned with a number of things in this passage, most notably waste. There is far too much waste in education when we leave it to individual teachers to figure out the art of teaching. While some teachers do-indeed - figure this art out (sometimes without the aid of teacher education), what about all of the other (non-exceptional) teachers, and what about the legacy of these exceptional teachers? The insight of these teachers lives and dies with them (or, as we shall see momentarily, can have a pernicious effect). Dewey would like to analyze how these teachers do what they do intuitively so that other teachers can learn from their experience. In its most simple form, this is what I mean in this paper by Dewey's thinking on a science of teaching. Though Dewey also mentions the importance of educational psychology for learning, and sociology for schools, he is also very interested in how the art of teaching can-through philosophical work [1] (pp. 26-27)—develop into the democratic common inheritance of as many teachers as possible. Expecting an objection to this aspiration, Dewey is quick to point out that this process is not meant to level down exceptional teachers to some common standard, but to give "common efficacy to the experience of genius". This is a striking line: we want to take the exceptional and make it part of our common possession. A deeply democratic concept-as we will see more explicitly in the next section-Dewey wants every teacher to share in that which exceptional teachers discover intuitively in practice. Again, the goal is not to set a uniform standard, but to continually raise the level of our common resources and to continue to learn from those exceptional teachers who will also benefit from a greater and more robust shared wisdom of teaching.

As noted above, Dewey is not only worried about the waste that occurs when we fail to make common what exceptional teachers do, the very idea of the exceptional teacher can have a pernicious effect. Dewey notes, in another rather long passage: 
The existence of scientific method protects us also from a danger that attends the operations of men of unusual power; dangers of slavish imitation partisanship, and such jealous devotion to them and their work as to get in the way of further progress. Anybody can notice today that the effect of an original and powerful teacher is not all to the good. Those influenced by him often show a one-sided interest; they tend to form schools, and to become impervious to other problems and truths; they incline to swear by the words of their master and to go on repeating his thoughts after him, and often without the spirit and insight that originally made them significant [1] (p. 5).

Instead of science, we create sects, take sides. Instead of learning from what the exceptional teacher finds and make it common to teaching, the exceptional teacher is revered and followers become locked in imitation; an imitation that lacks "the spirit and insight" that made the exceptional teacher's work noteworthy [18]. Sadly, Dewey seems to be on to something important here. We avoid a science for fear of leveling the profession to its lowest common denominator, but this fear often causes us to fall into an equally flawed stance: we offer a second-rate imitation of a great teacher and fight with others so that "our way" of teaching—or more, "our teacher"—is seen as better than any other. Instead of collaboration and commonality, we get competition; instead of insight that pushes the work of teaching forward, we get "slavish imitation". This is a key point. The exceptional teacher objection to a science of education not only leads to great waste, it leads to an unhelpful partisanship. Fearing the risk of conformity that may come about through the creation of a science of teaching, we fall into an even worse-because often blind-conformity to the exceptional teacher and a partisanship that keeps us from improving teaching, and so realizing that which is "worthy of the name education" [19] (p. 62).

This is one reason why I see Individualism Old and New as something of a companion piece to Science of Education. Though education is not the central focus of Individualism, Dewey analyses-in this work-how outmoded inherited notions of individualism that do not fit the present day keep us from creating the types of science that will allow for social and personal progress. To start, Dewey makes the case that the present era is different from the past; it is industrialized, corporate, interconnected. This should lead to the realization that "the problem of constructing a new individuality consonant with the objective conditions under which we live is the deepest problem of our times" [12] (p. 56). However, it is hard to create this individuality because our moral imaginations have not kept pace with the world we are living in. As Dewey notes:

Our material culture, as anthropologists would call it, is verging upon the collective and the corporate. Our moral culture, along with our ideology, is, on the other hand, still saturated with ideals and values of an individualism derived from the pre-scientific, pre-technological age. Its spiritual roots are found in medieval religion, which asserted the ultimate nature of the individual soul and centered the drama of life about the destiny of that soul [12] (p. 77).

Though Dewey is not writing about teaching directly here, it is easy to see how it can apply to much teaching that occurs today. Though the world around us is becoming more interconnected and more collaborative, the moral life of teaching tends to be bound up with the medieval drama of individual salvation. That is, instead of groups of teachers working together to improve the work of teaching [17], teachers tend to seek individual excellence in their own classroom. A teacher often seeks personal salvation —or personal excellence - and not the good of teaching (as a whole) or the good of the school she finds herself in. There are many reasons for this, and as collaborative as I can be at times, I know a picture of individual salvation holds me captive in many ways [20]. So, the point here is not blame, but to think with Dewey about the ramifications of holding onto a vision of individuality that may not fit the times we are living in.

It is important to consider if beliefs that were once useful—morally, personally and socially—in an age very different from the one we are living in now still have practical value [21]. Dewey is direct in his assessment: "Traditional ideas are more than irrelevant. They are an encumbrance; they are the chief obstacle to the formation of a new individuality" [12] (p. 86). Note here that Dewey is not 
against individuality, he is interested in forming an individuality that is consonant with the times we are living in. Holding on to the drama of salvation; of the isolated individual bootstrapping a way to goodness, given the time we are living in, just does not make sense. More, these visions are actually harmful, because they keep us from making progress. Dewey again remarks that "progress will not be initiated until we cease opposing the socially corporate to the individual, and until we develop a constructively imaginative observation of the role of science and technology in actual society" [12] (p. 89). Science in general-like a science of education discussed above and the science of teaching I am advocating for-comes about when we are interested in learning from the advances made by individuals, and making them a part of our collective wisdom and store of resources. When done well-according to Dewey-it is hard to see where the individual scientist and the work of science begins and ends. The scientist draws on what is known, and as new discoveries are made, they are then brought into the fold of advancing knowledge so that new discoveries can be made. Personal discovery becomes public good [13] (esp. Chapter 10). The medieval notion of private salvation becomes a stumbling block to this vision of individuals working out of interest in a type of work that is both personally rewarding and collectively valuable [13] (esp. p. 361). We must-according to Dewey-overcome outmoded visions of individuality, and embrace a future where we work together to turn the successes of individuals into a common, public, good. Fear, though, stands in the way.

The mind that is hampered by fear lest something old and precious be destroyed is the mind that experiences fear of science. He who has this fear cannot find reward and peace in the discovery of new truths and the projection of new ideals. He does not walk the earth freely, because he is obsessed by the need of protecting some private possession of belief and taste. For the love of private possessions is not confined to material goods [12] (p. 118).

I find this-again-an interesting connection to Sources of a Science of Education. There is something seductive about being the good teacher; the best teacher in a school, or the best in a certain grade-level or the best in a certain subject. However, where does this type of feeling lead? Though we may remain the best teacher as we define it, what about the experience students have with other teachers? Might we become better if we humbly share what seems to work for us while also listening to the insights of those who may not initially appear to be as compelling as we are? Do we fear creating a science of teaching because of all we may have to learn; because we may find it hard to accept that salvation-or excellence-comes about through collaboration, and not through competition or pridefully holding onto our current stage of development in the face of what could become through endless progress? Competition and complacency have no place in education [22]. As Dewey writes, "There is a subterranean partnership between those who employ the existing economic order for selfish pecuniary gain and those who turn their backs upon it in the interest of personal complacency, private dignity, and irresponsibility" [12] (p. 117). This is a jarring reminder to all of us teachers who choose our present state of excellence instead of seeking the better-personally and socially-through collaboration. As I will show in the next section, this is not a position that Dewey only espouses in his later work, it finds a powerful expression in Democracy and Education.

\section{Democracy and Teaching}

Teachers resist collaboration in the creation of a science of education not only because of the outmoded morality that puts personal salvation first; teachers resist collaboration for political and other moral reasons. As William James recognized well over one hundred years ago [23] teachers are bombarded with fads. It is often more pedagogically sensible to close the classroom door and do one's work than attend in-service meetings where school leaders promote the next thing pedaled by educational consultants and so-called edupreneurs; especially when teachers are then expected to adopt these practices, even though they go against what teachers know-with justification-about teaching and what works for students [24]. In addition to practical concerns about educational fads, teachers often have political reasons to resist collaboration around top-down reform efforts [25]. As reforms 
seem to change every few years, it is easy to imagine why a veteran teacher would not want to collaborate to create a new curriculum around a reform idea that may become obsolete in a matter of years. Again, instead of seeking collaboration, teachers can become demoralized given the pace and—often—disrespectful tone that many reform efforts take toward teachers [26]. Finally, the idea of a science of teaching can be called into question by teachers as they see waves of "evidence-based" practices come and go with little noticeable positive impact on the lives of students or schools [27]. As such, the usage of the language of evidence-based practice can feel like little more than a smokescreen for political and ideological agendas. This—in turn—can make the idea of a science of education seem like more of the same; certainly not something worth a teacher's time.

Dewey recognized these as problems, and Democracy and Education makes it clear that democracy is the key to progress; it is impossible to create a science of education-or grow as people and as a society-without democracy. Just as Dewey warns that the "exceptional teacher" paradigm stands in the way of progress, so too does top-down, non-collaborative approaches to improving teaching. Teaching will not improve without the presence of a strong democracy. This point is made from the beginning of Democracy and Education [13] (esp. pp. 8-12), but it receives its fullest treatment in Chapter 7, "The Democratic Conception in Education". In this section, I will look closely at two main passages from this chapter, track its development in other key passages from Democracy and Education, and then conclude by showing that Dewey's position in his later works Sources of a Science of Education and Individualism Old and New are clearly not deviations from the work started in Democracy and Education, but important steps in making nascent themes more explicit.

In Sources of a Science of Education, Dewey is concerned with creating something that is common to teachers; not something that is the sole possession of the exceptional teacher. In Democracy and Education, Dewey has the same concern, but on the largest possible scale. A society where we do not hold things in common is really no society at all. As Dewey notes, "We are thus compelled to recognize that within even the most social group there are many relations which are not as yet social" [13] (p. 8). This thought gets developed —at length—in the first quote I will consider from Chapter 7.

In order to have a large number of values in common, all the members of the group must have an equable opportunity to receive and to take from others. There must be a large variety of shared undertakings and experiences. Otherwise, the influences which educate some into masters, educate others into slaves. And the experience of each party loses in meaning, when the free interchange of varying modes of life-experience is arrested. A separation into a privileged and a subject-class prevents social endosmosis [13] (p. 90).

While Dewey's concern here is society at large, I want to bring this quote back into teaching. There are at least two levels at which this quote can be appreciated. The first is the policy level. Teachers often feel as if they have no voice in policy conversations; there is not an "equable opportunity to receive and take from others". As such, the experience of each party loses meaning: policy-makers lose out on the insights of teachers; teachers lose out on the insights of policy-makers. Though resistance to fads and ideology wrapped up as evidence-based practice is important, it is equally important to remain open to advances made by research and distilled into policies. Because there are not equable opportunities to share what is known, social endosmosis results. This, though, is not the focus of my essay; I want to start a little smaller. I want to start at the level of the school, or the district, or the county. We have to wonder how many values teachers at this level hold in common. Though lesson study [17] and practices such as descriptive review [28] encourage teachers to collaborate with each other, the sway of the "exceptional teacher model" seems to dominant many other school settings. That is, teachers isolate themselves from each other, and this arrests "the free interchange of varying modes of life-experience". When this happens, divisions harden-the good teachers, the less good teachers-and possibilities for developing common knowledge are foreclosed. If this is what happens within a school or a county, how much more so does this happen across the practice of teaching as a whole [11]? The immediate lesson of this quote, then, seems relatively simple: without effective communication and a willingness to build something we can share in common, everyone suffers. 
Dewey writes, "Lack of the free and equitable intercourse which springs from a variety of shared interests makes intellectual stimulation unbalanced [13] (p. 90). Unbalanced intellectual stimulation leads some to feel like "masters" and others "slaves". Though this may not be the way we would like to think of teacher dynamics within a school, it is interesting to think with Dewey on just this point.

If Dewey is on to something here, if a failure to communicate leads to division, we have to look at all of the consequences. Not only does it keep us from creating shared resources [29] and common knowledge that we can all grow from and contribute to, "isolation makes for rigidity and formal institutionalizing of life, for static and selfish ideals within the group" [13] (p. 92). I hear immediate echoes of this sentiment in Dewey's later work discussed in the section above. When we fail to collaborate, we fall into sects and conflicts that have pernicious effects. Instead of seeking growth through educative communication, we hold to beliefs that arrest personal and social development. When we seek isolation-in any form - we invite stasis, and this will not lead to the improvement of teaching or learning. The only antidote to this state is democracy. Dewey writes:

A democracy is more than a form of government; it is primarily a mode of associated living, of conjoint communicated experience. The extension in space of the number of individuals who participate in an interest so that each has to refer his own action to that of others, and to consider the action of others to give point and direction to his own, is equivalent to the breaking down of those barriers of class, race, and national territory which kept men from perceiving the full import of their activity. These more numerous and more varied points of contact denote a greater diversity of stimuli to which an individual has to respond; they consequently put a premium on variation in his action. They secure a liberation of powers which remain suppressed as long as the incitations to action are partial, as they must be in a group which in its exclusiveness shuts out many interests [13] (p. 93).

This is a well-known quotation from Democracy and Education, and I hope that putting it in conversation with Dewey's later work on teaching casts some new light on its implications. Re-reading this quote through the lens of teaching makes me think of all of the ways in which teaching is not yet as democratic as it could be. There is not enough collaboration in teaching, and because of this, nascent powers are not liberated; while a teacher may be good-even excellent—in isolation from his or her peers, so long as she remains isolated, she foregoes possibility. A diversity of stimuli-good, bad, neutral-represent opportunities-in-action. Interest in responding well to the variety that exists within a school should be a teacher's aim. While what a teacher currently does may work, Dewey wants us to appreciate the unforeseen possible that only comes about by diversifying the contacts of life that we invite and respond to.

Once we see this, then it becomes a moral imperative to seek out diversity: to communicate across difference so that our experience is changed, and to listen across difference so our store of resources expands and develops. As Dewey famously closes Democracy and Education: "All education which develops power to share effectively in social life is moral. It forms a character which not only does the particular deed socially necessary but one which is interested in that continuous readjustment which is essential to growth. Interest in learning from all the contacts of life is the essential moral interest" [13] (p. 370). I cannot imagine a better credo for a teacher. Note, it is not that Dewey is claiming that we will indeed learn from all of the contacts of life, but we have to be open to them: we have to take an interest in learning from all the contacts of life. Teaching in isolation keeps this from happening. What is needful is a community of teachers, a community for a teacher that extends far outside of the school, a community that allows each teacher to test her beliefs and practices and-when necessary-readjust these so that she is continuously growing. More, this growth cannot remain her private possession: it must be communicated, and through the process of communication, expanded and brought into what we hold in common as teachers. This is clearly an idealistic vision, and it is one that is often not promoted-or even thwarted—by short-sighted educational policies [30]. As important as policy and politics are, Dewey—in Democracy and Education-returns us to the moral dimensions of teaching [31] which are within a teacher's control. Here is how Dewey puts it: 
the idea of perfecting an "inner" personality is a sure sign of social divisions. What is called inner is simply that which does not connect with others-which is not capable of free and full communication. What is termed spiritual culture has usually been futile, with something rotten about it, just because it has been conceived as a thing which a man might have internally-and therefore exclusively. What one is as a person is what one is as associated with others, in a free give and take of intercourse. This transcends both the efficiency which consists in supplying products to others and the culture which is an exclusive refinement and polish ... There is no greater tragedy than that so much of the professedly spiritual and religious thought of the world has emphasized the two ideals of self-sacrifice and spiritual self-perfecting instead of throwing its weight against this dualism of life. The dualism is too deeply established to be easily overthrown; for that reason, it is the particular task of education at the present time to struggle in behalf of an aim in which social efficiency and personal culture are synonyms instead of antagonists [13] (pp. 129-130).

I see this as a key to understanding Dewey's thinking both in Democracy and Education and in his later work discussed above. Though we may not explicitly identify as adherents of a spiritual culture, our morals are often still controlled by beliefs that animate that culture: the drama of personal salvation Dewey execrates in Individualism Old and New. Dewey could not be any stronger: spiritual culture (divorced from collaborative, democratic social action) has something rotten about it. Furthermore, though we might not identify our actions as driven by this culture, when we do not seek out the contacts of life with diligence, when we feel complacent with our current state of development, then-I worry-we are not living up to the promise of Dewey's philosophy of education. Instead of seeking individual salvation in isolation, we need to work for a democratic community of teachers. This sentence is intended to cut in many ways: teachers need to collaborate with teachers, philosophers of education - as teachers themselves-need to find ways to collaborate and learn from each other as teachers and university professors, and philosophers of education can do more to collaborate with teachers to bring about something like the science of teaching that Dewey envisioned and hoped to bring into existence.

\section{Toward a Democratic Community of Teachers?}

In light of the foregoing analysis, I think that Dewey would welcome current reform efforts to develop teaching and core practices of teaching rather than working to cultivate exceptional teachers $[2-4,11,17,28,29]$. Though there is some risk in uniformity when one develops practices of teaching that are meant to be held common by all teachers, Dewey is quite clear that the risks of going at teaching alone as individuals far outweigh the benefits of working collaboratively-democratically-to improve the practice of teaching. To return to the quotation that opens this essay, "Even in the things conventionally recognized as sciences, the insights of unusual person remain important and there is no leveling down to a uniform procedure ... the existence of science gives common efficacy to the experiences of the genius". This is the hope. Without a science of education, there is waste and partisanship; when we hold the practice of teaching in common, exceptional teachers are not leveled down. However, there is the expectation that these exceptional teachers will seek to communicate their experience so that this experience is broadened and reconstructed for the individual, as it also becomes part of our common knowledge.

Saying this, Sharon Feiman-Nemser, in an excellent essay on Democracy and Education that directly addresses some of the forms of teacher education that I endorse above [32], is concerned that philosophical aims might get neglected when we teach future teachers those practices that are found to work most effectively in the classroom. The concern is that a science of education will treat philosophies of education as irrelevant or lacking sufficient utility. Though this is a risk that we would have to assess in practice, before shutting down the very idea of this type of project, we have to hold in mind that Dewey would never endorse the abandonment of philosophy in the education of teachers. Instead, Dewey wants both: he wants a science of teaching where philosophies of education play 
important roles. However, if philosophy of education is to play a role in the development of a science of education, the role must be a collaborative democratic one. Philosophers of education need to take an interest in learning from what is happening in classrooms, and take the risk of enacting ideas and aims in the difficult world that is the practice of teaching [33]. Dewey puts it this way in Sources of a Science of Education:

It is not enough to criticize the narrow limitations of accepted ends and values. This needful task is but the negative side of the function of suggesting new ends, new methods, new materials. In performing this office, provision of scope of estimate and liberation of mind comes to a head. As far as the philosophy of education effects anything important, this is what it accomplishes for those who study it. Ideas are ideas, that is, suggestions for activities to be undertaken, for experiments to be tried [1] (p. 30).

Here is where democratic collaboration becomes exceedingly important for philosophers of education. It is not enough to criticize existing approaches to teaching or teacher education; one can do this relatively effectively from the outside, at a remove from the work of schools. To test educational experiments, one must have partners willing to undertake those experiments. One cannot dictate these from above; teachers-as noted above-are tired of being told what to do; they are used to this un-democratic process. What is necessary is conversation; a democratic conversation that educates each party involved.

I see a major opening for this conversation in Mary Kennedy's recent work, "Parsing the Practice of Teaching" [5]. Kennedy-like complementary approaches to creating a science of teaching based on core practices that every teacher needs to enact in the classroom-lists five things that effective teachers do in the classroom:

- They portray curriculum content in a way that renders it comprehensible to naïve minds;

- For students who are not necessarily interested in learning;

- And whose grasp of the content is not readily visible to the teacher;

- And who are restless and easily distracted;

- In a way that satisfies the teachers' personal needs [5] (p. 13).

However, she goes one step farther. She argues that a teacher cannot do all of these things equally well and at all times. While every teacher needs to be able to do these five things: sometimes managing restless and distracted behavior will be paramount; at others, sparking interest is more important than control, and so on. As the literature on teaching has demonstrated, teachers face dilemmas that cannot be "solved"; they can only be managed in better and worse ways [34]. In addition to helping teachers think through these dilemmas philosophically [35], philosophers of education can study the new practices that may emerge when dilemmas are managed in ways that feel more-rather than less-successful. These practices can then become part of the store of knowledge that we can teach future teachers, just like the five components Kennedy lists above.

We do not want the waste that Dewey's describes in Sources of a Science of Education. If teachers find ways to successfully manage the dilemmas present in the classroom, this wisdom should not live and die with them. Rather, philosophers of education can develop and deepen conversations with teacher educators, advocating core practices that have yet to be theorized and integrated into teacher education programs. To do this, though, philosophers of education need to see the development of a science of teaching as something worthwhile to create, and think about what it would mean to be a democratic partner in its development. I want to close by making two suggestions. First-and probably most simple-philosophers of education can begin to engage more fully with developments in teacher education, developments-as I hope to have demonstrated here-Dewey would be heartened by. The very title "Teaching, Rather than Teachers, As a Path Toward Improving Classroom Instruction" [11] would—I feel—be intriguing to Dewey. The second-and here more difficult-thing that philosophers of education can do is to test how democratic our own work is and 
can be as teachers. When it comes to believing in the importance of the exceptional teacher, where do we stand? Are we some of the greatest adherents and aspirants? If so, what might we learn by making the attempt to see our work as democratic and not individualistic in the sense criticized by Dewey? Can we collaborate democratically with secondary and elementary teachers if we find it tremendously difficult to even begin collaborating-around teaching and teaching practices-with each other? The call to create a democratic community of teachers is not one that I see Dewey asking us to facilitate on the sidelines, as it were. It is something that he calls us to do together, now, as teaching philosophers of education.

All this leads to what may be the most important implication of this paper. If we have a hard time imagining teaching as a democratic and not individual act, then I think we are left in an interesting position. We are in a position where we can push past our initial unease and work toward the democratic community of teachers that Dewey hopes to bring into being, or we might find ourselves in the position of wondering just how much we agree with Dewey when it comes to teaching and teacher education. If my paper has done anything, I hope that it has provoked thought on just this point. That is, if my interpretation of Dewey is correct when it comes to what he hopes for when it comes to teaching, then I think that we should either work toward this vision or offer the strongest possible criticism of it. Not just for the sake of literature in our field, but as a means of speaking back to dominant discourses in the teacher education literature. Revisiting Democracy and Education through the lens of teaching offers us opportunities to enact change in the direction of Dewey's hope and it also opens new avenues for criticism. It is my modest hope that the current paper encourages this work, regardless of the direction it takes, because I feel that it is as important, now as ever, that philosophers of education have a voice in conversations about teaching and teacher education.

Conflicts of Interest: The author declares no conflict of interest.

\section{References}

1. Dewey, J. Sources of a Science of Education. In The Later Works of John Dewey, Volume 5; University of Southern Illinois Press: Carbondale, IL, USA, 2008.

2. Green, E. Building a Better Teacher; WW Norton: New York, NY, USA, 2015.

3. Forzani, F.M. Understanding "Core Practices" and "Practice-Based" Teacher Education: Learning from the Past. J. Teach. Educ. 2014, 65, 357-368. [CrossRef]

4. Ghousseini, H. Core Practices and Problems of Practice in Learning to Lead Class Discussions. Elem. Sch. J. 2015, 115, 334-357. [CrossRef]

5. Kennedy, M.M. Parsing the Practice of Teaching. J. Teach. Educ. 2016, 67, 6-17. [CrossRef]

6. D'Agnese, V. The Essential Uncertainty of Thinking: Education and Subject in John Dewey. J. Philos. Educ. 2016. [CrossRef]

7. Burbules, N.; Hansen, D. Teaching and Its Predicaments; Westview Press: Boulder, CO, USA, 1997.

8. Floden, R.; Buchmann, M. Between Routines and Anarchy: Preparing Teachers for Uncertainty. Oxf. Rev. Educ. 1993, 19, 373-382. [CrossRef]

9. Jackson, P. Facing Our Ignorance. Teach. Coll. Rec. 1987, 88, 384-389.

10. Jackson, P. Practice of Teaching; Teachers College Press: New York, NY, USA, 1986.

11. Hiebert, J.; Morris, A.K. Teaching, Rather than Teachers, As a Path Toward Improving Classroom Instruction. J. Teach. Educ. 2012, 63, 92-102. [CrossRef]

12. Dewey, J. Individualism Old and New. In The Later Works of John Dewey, Volume 5; University of Southern Illinois Press: Carbondale, IL, USA, 2008.

13. Dewey, J. Democracy and Education. In The Middle Works of John Dewey, Volume 9; University of Southern Illinois Press: Carbondale, IL, USA, 1985.

14. Lortie, D. Schoolteacher: A Sociological Study; Chicago UP: Chicago, IL, USA, 1975.

15. Brewer, T.J.; Myers, P.S.; Zhang, M. Islands unto Themselves: How Merit Pay Schemes May Undermine Positive Teacher Collaboration. Available online: http:/ files.eric.ed.gov/fulltext/EJ1065822.pdf (accessed on 6 August 2016). 
16. Hargreaves, A. Presentism, Individualism, and Conservatism: The Legacy of Dan Lortie's Schoolteacher: A Sociological Study. Curric. Inq. 2010, 40, 143-154. [CrossRef]

17. Lewis, C.; Perry, R.; Murata, A. How Should Research Contribute to Instructional Improvement? The Case of Lesson Study. Educ. Res. 2006, 35, 3-14. [CrossRef]

18. Emerson, R.W. Essays and Lectures; Library of America: New York, NY, USA, 1983.

19. Dewey, J. Experience and Education. In The Later Works of John Dewey, Volume 13; University of Southern Illinois Press: Carbondale, IL, USA, 2008.

20. Wittgenstein, L. Philosophical Investigations, 4th ed.; Blackwell: New York, NY, USA, 2009.

21. James, W. Pragmatism. In Pragmatism and the Meaning of Truth; Harvard University Press: Cambridge, MA, USA, 1978.

22. Dewey, J. Moral Principles in Education in Democracy and Education. In The Middle Works of John Dewey, Volume 4; University of Southern Illinois Press: Carbondale, IL, USA, 1985.

23. James, W. Talks to Teachers. In William James: Writings 1878-1899; Library of America: New York, NY, USA, 1992.

24. Doyle, W.; Ponder, G.A. The Practicality Ethic in Teacher Decision-Making. Interchange 1977, 8, 1-12. [CrossRef]

25. Gitlin, A.; Margonis, F. The Political Aspect of Reform: Teacher Resistance as Good Sense. Am. J. Educ. 1995, 103, 377-405. [CrossRef]

26. Santoro, D.A. Good Teaching in Difficult Times: Demoralization in the Pursuit of Good Work. Am. J. Educ. 2011, 118, 1-23. [CrossRef]

27. Biesta, G. Why "What Works" Won't Work: Evidence-Based Practice and the Democratic Deficit in Educational Research. Educ. Theory 2007, 57, 1-22. [CrossRef]

28. Carini, P.F. Starting Strong: A Different Look at Children, Schools, and Standards; Teachers College Press: New York, NY, USA, 2001.

29. Morris, A.K.; Hiebert, J. Creating Shared Instructional Products: An Alternative Approach to Improving Teaching. Educ. Res. 2011, 40, 5-14. [CrossRef]

30. Santoro, D.A. Teaching's Conscientious Objectors: Principled Leavers of High-Poverty Schools. Teach. Coll. Rec. 2011, 113, 2670-2704.

31. Hansen, D.T. Exploring the Moral Heart of Teaching; Teachers College Press: New York, NY, USA, 2001.

32. Feiman-Nemser, S. A Teacher Educator Looks at Democracy and Education. In John Dewey and Our Educational Prospect; Hansen, D.T., Ed.; SUNY Press: Albany, NY, USA, 2006; pp. 129-146.

33. Kennedy, M.M. The Role of Preservice Teacher Education. In Teaching as the Learning Profession; Darling-Hammond, L., Sykes, G., Eds.; Jossey-Bass: San Francisco, CA, USA, 1999; pp. 54-86.

34. Lampert, M. How do Teachers Manage to Teach. Harv. Educ. Rev. 1985, 55, 178-194. [CrossRef]

35. Levinson, M.; Fay, J. Dilemmas of Educational Ethics: Cases and Commentaries; Harvard Education Press: Cambridge, MA, USA, 2016.

(C) 2017 by the author; licensee MDPI, Basel, Switzerland. This article is an open access article distributed under the terms and conditions of the Creative Commons Attribution (CC-BY) license (http://creativecommons.org/licenses/by/4.0/). 